\title{
Proper Names and Belief Reports
}

\author{
Caleb Miller \\ University of Notre Dame
}

John Stuart Mill said of proper names that they are ". . not connotative; they denote the individuals who are called by them, but they do not indicate or imply any attribute as belonging to those individuals." "The sole semantic function of names on this view is to denote an individual, not to say anything about that individual. It follows from this that two proper names which refer to the same individual are semantically equivalent. The only semantic function they perform is exactly the same. One consequence of this is that coreferring names can be substituted in a sentence without changing what the sentence expresses. Let us henceforth call the thesis that co-referring names can be so substituted the substitutivity thesis.

Gottlob Frege held a view much like Mill's in his earlier work. ${ }^{2}$ He rejected it, however, at least in part because he was convinced that the substitutivity thesis created insuperable problems in accounting for certain data of cognitive significance." In this paper I shall begin by very briefly considering a Eregean objection to the substitutivity thesis. I shall then argue that the objection does not give us good grounds for rejecting the Millian thesis. I shall do so by offering an analysis of belief that allows us a plausible interpretation of the Fregean data that is consistent with a Millian position on proper names and substitutivity.

\section{The Fregean Objection}

The Fregean objection I am considering can best be seen by way of example. "Cicero" and "Tully" are, Quine assures us, different names of the same person. That means, according to the rubstitutivity thesis, that substituting one name for the other in a sentence will not change what the sentence. in question expresses. Thus

(1) Tully is an orator

and 


\section{(2) Cicero is an orator}

say the same thing, or express the same proposition. It seems obvious that it is possible for a person to believe (1) without believing (2). But inasmuch as the objects of belief are not sentences but the propositions expressed by sentences, it is the proposition expressed by (2) [hereafter, $p(2)$ ] that is believed while $p(1)$ is not believed. But that should be impossible on the substitutivity thesis. According to it, $p(1)$ and $p(2)$ are identical. To believe $p(2)$ just is to believe p(1).

\section{The Independence of Semantic and Cognitive Consid- erations}

Howard Wettstein, who advances a basically Millian view of proper names, has recently proposed an interesting approach to the Fregean problems of cognitive significance." He has suggested that these problems ought not to be seen as semantic problems. While he elaborates a construal of the semantic enterprise which I shall not consider here, his suggestion can usefully be appropriated as a thesis about the independence of the reference of proper names from the cognitive significance of those names or of the sentences in which they appear.

Wettstein argues that there is no reason to suppose that a thesis about the reference of proper names entails anything about the cognitive significance of those names. A theory of reference, on his construal of semantics, has to do with a relationship between language and the world, whereas cognitive problems involve a relationship between the mind and language or perhaps the mind and the world. Two names might corefer and thus on the Millian view be semantic equivalents, and yet the way in which a person thinks about their common referent may be very different depending on which word he is using. Analogously, two sentences containing such co-referring names might similarly express the same proposition despite the fact that a particular person has widely different cognitive perspectives on it.

Wettstein claims that this independence between cognitive and semantic considerations allows us to see that while "cognitive puzzles" of the sort I mentioned above are phenomena in need of explanation, they ought not to pose a problem for one's view of reference. The sort of explanation they require is not a semantic explanation but a cognitive one. Thus (1) and (2) might in fact express the same proposition while the way in which a given individual cognizes that proposition may vary greatly depending on whether the proposition is expressed by (1) or by (2). So the Millian can accept without qualms the intuition that sentences (1) and (2) 
individuate different cognitive or mental states without the semantic thesis that the "Cicero" and "Tully" sentences both express the same proposition.

While Wettstein's general claim that cognitive matters are independent from reference seems plausible to me, it does not obviously follow from that claim that the substitutivity thesis is invulnerable to criticism on cognitive grounds. Recall the Cicero-Tully puzzle. If the substitutivity thesis is true, then co-referring names should be interchangable salva veritate in sentences. But it seems obviously possible that

(3) S believes that cicero is an orator

is true, and

(4) S believes that Tully is an orator

is false. Since "Cicero" and "Tully" are co-referring, the substitutivity thesis requires that $p(3)$ and $p(4)$ are identical. But that seems obviously false, since they apparently have different truth values. We seem to have a counter-example to a semantic thesis based solely on cognitive considerations.s

So even if, as Wettstein plausibly suggests, a thesis about reference need not imply any account of cognitive matters, there nevertheless remain serious problems for the substitutivity thesis that require only cognitive assumptions." These problems, moreover, can be adequately addressed only by further analyzing the nature of belief. It is to that enterprise that I now turn.

\section{Kripke's Account of the Puzzle}

Saul Kripke has argued that a puzzle about belief similar to the puzzle we saw in the "Cicero-Tully" case can be shown to arise without making any assumptions at all about substitutivity.' One case he considers requires only that we accept the common-sense disquotational principle: for any appropriate English sentence p. "If any English speaker, on reflection, sincerely assents to ' $p$ ', then he believes that $p$." ' ' $\mathrm{P}$ ', of course, cannot be a sentence containing pronominal or indexical elements that would weaken the intuitive force of the disquotational principle. Thus, for example, I cannot validly infer from someone else's sincere utterance of "I am hungry" that he believes that I am hungry.

Kripke constructs the following case.' Peter learns the name "Paderewski" with an identification of Paderewski as a famous pianist and, not surprisingly, assents to "Paderewski had musical talent." From this we can infer, using the disquotational principle, that 
(5) Peter believes that Paderewski had musical talent.

Later, in another context, Peter learns of a Polish national leader named "Paderewski." Peter does not know that the musician and the statesman are the same person and believes that statesmen are rarely possessed of musical talent. Thus, he assents to "Paderewski had no musical talent." From this we can infer, again using the disquotational principle, that

(6) Peter believes that Paderewski had no musical talent.

We conclude, therefore, that Peter has contradictory beliefs. But this conclusion seems counter-intuitive in view of the fact that no amount of logical acumen will enable Peter to eliminate the contradiction. But a straightforward contradiction is the sort of thing that is usually transparent even to a person who is completely ignorant of formal logical rules.

By strengthening the disquotational principle only slightly we get even more surprising results. The strengthened disquotational principle ${ }^{10}$ adds to the disquotational principle the provision that "If a normal English speaker, on reflection, sincerely dissents from ' $p$ '. then he does not believe that $p . "$ It is really something like this strengthened disquotational principle that generated the Cicero-Tully puzzle. The disquotational principle itself gives us no rules for determining what a person does not believe but only for determining what he does believe. One could never conclude on the basis of it that a person did not believe $p(1)$. For such a conclusion we need something like the strengthened disquotational principle.

Now, let us change Kripke's example so that instead of Peter assenting to "Paderewski had no musical talent," he dissents in the same situation from "Paderewski had musical talent." From this we can infer, using the strengthened principle, that

(7) Peter does not believe that Paderewski had musical talent.

But (7), of course, contradicts (5) and this is a contradiction, not only in Peter's beliefs, but also in our own. The simple application of the strengthened disquotational principle to this case yields straightforwardly contradictory results.

This, then, is the dilemma. Either we take Peter's sincere assent to and dissent from sentences to be a reliable guide to what he does and does not believe, which leads us to a contradiction, or we deny either (7) or (5) and so give up the assumption that Peter's assent and dissent is a reliable guide to his beliefs. 
Let us consider the latter choice first. The strengthened disquotational principle is nothing like a necessary truth.'1 If, for example, ' $p$ ' is a sentence that the relevant English speaker misunderstands, his sincerely assenting to ' $p$ ' is compatible with his not believing that $p$. Even if he knows that he does not understand ' $p$ ', he might still sincerely assent to it if he has it on good authority that ' $p$ ' is true. But what that tells us is, not that he believes that $p$, but that he believes that ' $p$ ' expresses a truth. But none of these problems with linguistic competence affect the "Paderewski" case. Peter understands what each of the relevant sentences means. There seems to be no good reason for denying that the strengthened principle applies to the "Paderewski" case without denying that it applies to any kind of case. But that seems a radical conclusion, since it seems that most of our judgments about what beliefs a person has or lacks depend centrally on knowing the sentences to which he assents and those from which he dissents. But if we accept the strengthened disquotational principle for determining Peter's beliefs we are forced to the other horn of the dilemma. That principle commits us to a contradiction. There seems to be no escape. But inasmuch as the dilemma arises without making any assumption at all about substitutivity we should not look for the source of the problem in the substitutivity thesis. We should rather look, I suggest, at the way in which beliefs are ascribed, since the puzzle can be generated by making assumptions only about belief ascriptions.

\section{A Proposed Solution}

We can, it seems to me, understand how such a problem arises and how it can be resolved by exploiting Wettstein's notion of a cognitive perspective.12 He pointed out that a person can believe or disbelieve a proposition from different cognitive perspectives, and that one's cognitive perspective may be independent of how a name refers and of what proposition a sentence expresses. What was not explicit in his discussion was the fact that whenever a person believes a proposition, he believes it from some cognitive perspective or other. Cognitive perspectives on propositions are in this sense analogous to visual perspectives on physical objects. Whenever a person sees an object, he sees it from some perspective. The same object can be seen from different perspectives, but can be seen only from some perspective or other. Likewise, the objects of belief, i.e., propositions, can be believed only from some perspective or other though they can be believed from more than one perspective. Whenever the two-place relation of belief obtains between a person and a proposition, another three-place relation obtains among that person, that proposition, and a cognitive 
perspective. In other words a person believes a proposition just in case there is at least one cognitive perspective such that the person believes the proposition from that perspective. But just as an object can be seen by the same person from different perspectives, so the same proposition can be believed or disbelieved from different perspectives. A person will, for example, be likely to have different perspectives on a proposition if he has different perspectives on the referent of proper names occurring in sentences expressing the proposition. An explicit recognition of this goes a long way toward solving Kripke's puzzle.

It is not ordinarily necessary or useful to specify the cognitive perspective from which a proposition is believed or to distinguish it from other perspectives on the proposition. But making such distinctions will be very useful here. Keeping in mind this distinction between believing a proposition and one's perspective on the proposition, it is obvious that while it follows from believing a proposition that it is believed from some perspective, it does not follow that it is believed from all the perspectives one has on the proposition. Peter had two different cognitive perspectives on Paderewski and consequently two different perspectives on the proposition expressed by "Paderewski has musical talent." He believed that proposition from only one of those perspectives. It should not be surprising that Peter believes its negation from another perspective on Paderewski. His having contradictory beliefs initially seemed counter-intuitive because straightforward contradictions are normally transparent. It seemed therefore that only a minimal awareness of logic should enable Peter to recognize and correct the contradiction in his beliefs. Yet it was obvious that no level of logical expertise would be of any help to him.

But now it becomes clearer how it is that Peter could have a contradiction among his beliefs of which he is not aware. He assented to the relevant sentence from one cognitive perspective on the proposition it expressed and assented to its negation from a different perspective on the proposition. From each of the two relevant perspectives on Paderewski, Peter is unaware that the musician is the same person as the statesman. These different perspectives on Paderewski. give Peter different perspectives on the proposition expressed by "Paderewski had musical talent." From one such perspective he is unaware that the sentence expresses the same proposition as it does from the other perspective. What follows from the application of the disquotational principle to this case is indeed that Peter believes both a proposition and its regation, but we can see now that the perspective on the proposition from which he believes it is different from the one from which he believes its negation. Since he is unaware that they 
are perspectives on the same proposition, he is unaware that his beliefs are contradictory. Although his beliefs are contradictory they are not necessarily irrational since the contradiction results from a lack of information rather than a deficiency in his logic.

But what then are we to make of the strengthened disquotational principle? It yielded, as we saw, a contradiction in our own judgments about Peter's beliefs, a contradiction, moreover, of which we were perfectly well aware. My suggestion in this case is that the strengthened principle no longer seems plausible if we are cognizant of the relation between cognitive perspectives and beliefs. Peter assents to "Paderewski had musical talent" from one perspective on the proposition it expresses and dissents from the sentence from another perspective on it, though the sentence, in both cases, expresses the same proposition. According to the strengthened principle, Peter both believes and does not believe the same proposition. I suggest that we should conclude, not that he both does and does not believe the proposition, but that he believes it from one perspective and does not believe it from another perspective. This judgment is not contradictory. It should not even be particularly surprising in view of the fact that Peter does not know that these two perspectives are perspectives on the same proposition. To be sure, his beliefs are in some sense inconsistent. but he is not therefore irrational because the inconsistency results again from a lack of information rather than a logical deficiency.

\section{A Kripkean Objection}

Kripke says that it is no solution to the puzzle about belief to give an account of Peter's beliefs in some other vocabulary. There are, he suggests, some such descriptions of Peter' $g$ bellefs that are in some sense complete, but do not solve the puzzle because they do not answer the question, "Does Peter or does he not believe that Paderewski had musical talent?"13 It might seem that I have offered just such an account. What I have said about Peter is that he believes from one cognitive perspective that Paderewski had musical talent and that he does not believe it from another perspective. Could we not still ask, "But does he. or does he not believe that Paderewski had musical talent?"

Fortunately, my account can answer even that question. Peter does indeed believe that Paderewski had musical talent. It is not the case that he does not believe it. An analogy will be helpful here. "Scroggins wears a ring" is true if there is at least one of Scroggins' fingers upon which he wears a ring. Now it might be true both that Scroggins wears a ring on his left ring finger and that he does not wear one 
on his right index finger. Could a person not say in such a situation: "I know that Scroggins wears a ring on one finger and does not wear one on another finger. But the question remains, does he or does he not wear a ring?" Of course, Scroggins wears a ring. His wearing a ring requires no more than his wearing a ring on at least one finger.' His not wearing it on another finger implies only that he does not wear a ring on that finger, not that he does not wear a ring. For that to be the case he must not wear a ring on any of his fingers.

Similarly, Peter believes the proposition expressed by "Paderewski had musical talent" just in case there is at least one cognitive perspective from which he believes it. Since Peter believes that proposition from one perspective, he believes it. To be sure, he also does not believe it from another perspective. He even belies its negation from that perspective. But it is nevertheless false that he does not believe it. He does believe it, but the perspective from which he believes it is not the one from which he believes its negation. All that is required for him to believe a proposition is that he believe it from some perspective or other. Thus we cannot necessarily infer from his sincere dissent from a sentence expressing this proposition that he does not believe it at all. It is safe only to infer that he does not believe it from his current perspective.

These insights allow us to resolve the cognitive problems for the Millian substitutivity thesis. That thesis, as we saw, entalied that substituting coreferring proper names in declarative sentences does not change the proposition that such sentences express. This was a problem, first of all because such substitution in (1) and (2) seemed to make possible believing p(2) without believing $p(1)$, which implied that $p(1)$ and $p(2)$ are not identical and that therefore the substitutivity thesis is false. Secondly, the substitutivity thesis seemed obviously to be falsified by the substitution of co-referring names in belief reports. The thesis implied that (3) and (4) express the same proposition. Yet it seemed obvious that it was possible that $p(3)$ and $p(4)$ differ in truth value which implied that they are not identical.

Now we are in a position, however, to see that the cognitive assumptions behind the counter-examples to substitutivity are false. The reason that it seemed plausible to suppose that it is possible to believe $p(2)$ without believing $p(1)$ was that it seemed plausible to suppose that a person could sincerely assent to the former while dissenting from the latter. Now we can see that the previously unacknowledged inference from a person's dissenting to (l) to his not believing $p(1)$ is fallacious. The same fallacy grounds our belief that (3). could express a true proposition while 
(4) expressed a false one. The substitutivity thesis then remains unscathed by these objections, not because they are based on cognitive claims, but because those claims are false.

VI. Concluding Remarks

I have said little that might convince a Fregean that my analysis of the relationship among cognitive perspectives, belief, and propositions is correct. He will have no trouble accepting the fact that Peter has more than one cognitive perspective on Paderewski. He will, however, claim that the sentence "Paderewski had musical : talent" expressess a different proposition depending on which perspective the speaker or believer has on Paderewski. My point has not been to show that these cognitive data are inconsistent with a Fregean account but to show that they are consistent with the substitutivity thesis. I have not offered any arguments against a Eregean account. I have sought only to eliminate one significant Fregean argument against the substitutivity thesis. I began the paper by observing what seemed to be some obvious facts about belief that contradicted the substitutivity thesis. I have argued that an appreciation of the significance of cognitive perspectives makes it plausible to hold that those apparently obvious claims are false.

\section{NOTES}

${ }^{1}$ Collected Works of John Stuart Mill, ed. J. M. Robson, vol. 7: $\frac{\text { A System }}{1973 \text { ) }}$ of Logic (Toronto: University of Toronto Press, 1973), 33 .

${ }^{2}$ Translations From the Philosophical Writings of Gottlob Frege, ed. Peter Geach and Max Black, Begriffsschrift (Oxford: Basil Blackwell, 1980), 10-12.

"On Sense and Reference" in Translations from the Philosophical Writings of Gottlob Frege, 56-57.

"Howard Wettstein, "Has Semantics Rested on a Mistake" The Journal of Philosophy 83 (April 1986):

${ }^{5}$ Wettstein hints that he holds belief to be a relation, not between a person and a proposition, but a three-place relation among a person, an object, and a property. I think it is obvious that the same problem would arise on this view. If a proper name only serves to denote an object, then the substitution of co- 
referring names should not affect whether or not the belief relation holds between a person, the object denoted, and the property in question. (Wettstein, 198).

Wettstein acknowledges that he has not offered a solution to this problem. He suggests that perhaps the substitutivty thesis needs to be abandoned for proper names in belief reports while retaining it for proper names in simple sentences not embedded in belief reports. (Wettstein, 204-209).

Saul Kripke, "A Puzzle about Belief" in Meaning and Use, ed. A Margalite (Dordtrecht: 1979).

'Kripke, 249.

Kripke, 265-266.

Kripke also considers a strengthened disquotational principle. His is somewhat stronger than mine. (Kripke, 249).

${ }^{10} \mathrm{Kripke} / \mathrm{s}$ construal of the puzzle does not assume that this principle is necessarily true.

1'This notion is, of course, not original with Wettstein. It was for example, appropriated in earlier attempts to resolve cognitive puzzles by John Perry, ["The Problem of the Essential Indexical," Nous ij (1979)], and David Kaplan [Demonstratives (unpublished)]. It was differently appropriated for the same purpose by Frege ["On Sense and Reference"].

${ }^{22}$ Kripke, 259. 